\title{
Physical Rehabilitation, An Important Factor On The Treatment Of Multiple Scleroses: A Literature Review
}

\author{
Evis Allushi, PhD Candidate \\ Faculty of Public Health, University of Vlora "Ismail Qemali“‘, Albania \\ Ilirjana Zekja, Asc. Prof \\ Faculty of Technical Medical Sciences,University of Medicine, Tirana
}

\begin{abstract}
Multiple Scleroses (MS) is the most often neurological disability of the young adults in the world and most of the people are diagnosed between 20-40 years old. Rehabilitation is a component of the full management of MS focused on the preservation and function improvement and adds non pharmacological treatment in the care of the patients. The objective of this research was the review of the literature in relation to the physical rehabilitation as an important alternative in the treatment of MS. The research included the electronic data base of the libraries Ovid, PubMed, Cochrane Library, NLM Tools. The inclusion criteria were the published studies on the theme of physical rehabilitation as an important factor in the treatment of MS. More than 30 potential articles were identified, but we reviewed the results of seven articles related to the theme of interest. The review evidenced that the multidisciplinary rehabilitation in MS is effective ein the improvement of many daily activities and reduction of the disability. Most of the studies report improvement in the limited disability and life quality, but the deficit remains unchanged. Symptoms such as fatigue, spasticity, ataxia and sphincter disorders profit from the proper pharmacological studies applied together with rehabilitation therapy. MS affects more females than males. The physical rehabilitation is more effectively if it starts early, before the disease progression. Many clinical signs improve from the proper medical treatment combined with rehabilitation therapy. The literature showed some contrary facts related to the efficacy of various rehabilitation forms.
\end{abstract}

Keywords: Multiple scleroses, rehabilitation, multidisciplinary, disability 


\section{Introduction}

Multiple scleroses is the most often neurological disability of the young adults in the world. Multiple scleroses may develop at any age, but most of the people are diagnosed between 20-40 years old (Ann Pietrangelo \&Valencia Higuera, 2015).

Multiple scleroses (MS) (NINDS, 2001) are a group of degenerative diseases of the nervous system, which affect the brain and spinal cord. These diseases damage the myelin and its protective sheath. Eventually, the myelin starts to gets damaged in many areas leaving behind scars called patches. The damaged myelin reduces the ability of the nerves to transmit the nervous impulses from the brain to pheripheral areas and vice versa, generating disfunctions that interfere in the everyday life of the person.

Various studies still have not determined the real causes of MS, furthermore they have not found the reason why the scale of progression is so difficult to determine (Alberto G. et al., 2013; Ann Pietrangelo \&Valencia Higuera, 2015). What is positive is the fact that many people with MS do not end up with total disability, or the fact that most of them have normal or close to normal (MSF,2013; Ann Pietrangelo \&Valencia Higuera, 2015). MS affects around 2.5 million (WHO, 2008) people all over the world. It is one of the most frequent neurological disorders and the cause of limited disability among young adults, especially in Europe and North America, but its epidemiology is less studied in Asia.

Regardless of our knowledge of the considerable impact of MS, there is limited information related to global epidemiology, the sources for its diagnosing, informations, treatment, rehabilitation, support and ensure serveces to people with MS. For this reason WHO and the International Federation of MS launched a collaborative effort to determine the factors mentioned above. Between 2005 and 2007, 112 countries that represent $87.8 \%$ of the world population are questioned about MS as part of this approach. Data and the gathered information show clearly that none of the countries offers neccessary resources and the availability of the resources varies widely within the region and worldwide. But in 2013, this survey was repeated and it was noted that the number of people with MS went from 2.1 million in 2008 to 2.3 million in 2013 (MSIF, 2013). It is unclear if this raise comes as a result of a better diagnosing and report of the cases, or another reason.

According to the MS International Federation the clinical signs a person with MS has are: tiredness, pain, bowel and bladder issues, sexual disfunction, movement and coordination problems, visula and recognition problems, emotional changes.

However, every neurological symptom or sign may be part of MS of a person. Some of the symptoms are obvious imediately, but others as 
tiredness, memory and concentration problems often are less obvious. These may be hadt to describe to others and sometime the family and the caregivers do not understand the effects of these symptoms on the person with MS, employment, social activities and quality of life.

\section{The prevalence situation of MS in Albania}

The first study is conducted in 1980-1988 (Kruja $\mathrm{J}$ et al.,2012); the prevalence of Multiple Scleroses resulted in 10.3/100.000 (0.1/1000) residents for determined possible cases, according to Rose et al. and $12.5 / 100.000$ (0.12/1000), including suspected cases. A small group was also found in the South East side of Albania. During 2008, there were 9869 people with MS (Tiranë 4953; Sarandë 4916). The prevalence was higher in Sarandë (South West).

Rehabilitation (MSIF, 2013) is part of MS management which focuses in the preservation and improvement of the function. For many people with MS the pharmacological therapy alone is not enough to properly treat the individual symptoms or in some cases the progress of the disease. The rehabilitation is a component of full MS management focused in the body function and adds the non pharmacological strategies for the care of the individual. The MS rehabilitation aims to encourage the indepedence and to improve the quality of life through the program oriented goals that include the individual with MS and to determine the treatment priorities. To ensure the effectiveness of rehabilitation it is important that all members of the medical team work together. The team should include the individual with MS and their families, who should work closely with multidisciplinary specialized experts including professionals, technical equipment and professional counceling. Collaboration within the team aims to create a plan that ensures the fullfillment of the needs of MS patient, keeping in mind the priorities, the way of life and the patient's wishes. However, rehabilitation (MSIF, 2015) plays a major role in the long term treatment and support of these patients for years to go.

\section{Method and materials}

The objective

To review the literature in relation to the physical rehabilitation as an important alternative in the treatment of MS.

\section{The research procedure}

The systematic electronic research for the published articles without a time limit was performed during January to February 2016 (see Figure1). Research included the electronic databases of: Ovid PubMed, Cochrane Library, NLM Tools. The key words referred to the factors that affect the 
rehabilitation of the MS patients as rehabilitation, MS, physiotherapy, intervention etc. The articles included were only in English. More than 30 potential articles were identifed, but we reviewed the original results of seven publications related to the interested theme. The final review of the articles was done independently from the authors in order to reduce the mistakes. The research was conducted in concordance with the instructions of the systematic review of the literature (Higgins J \& Green S 2008).

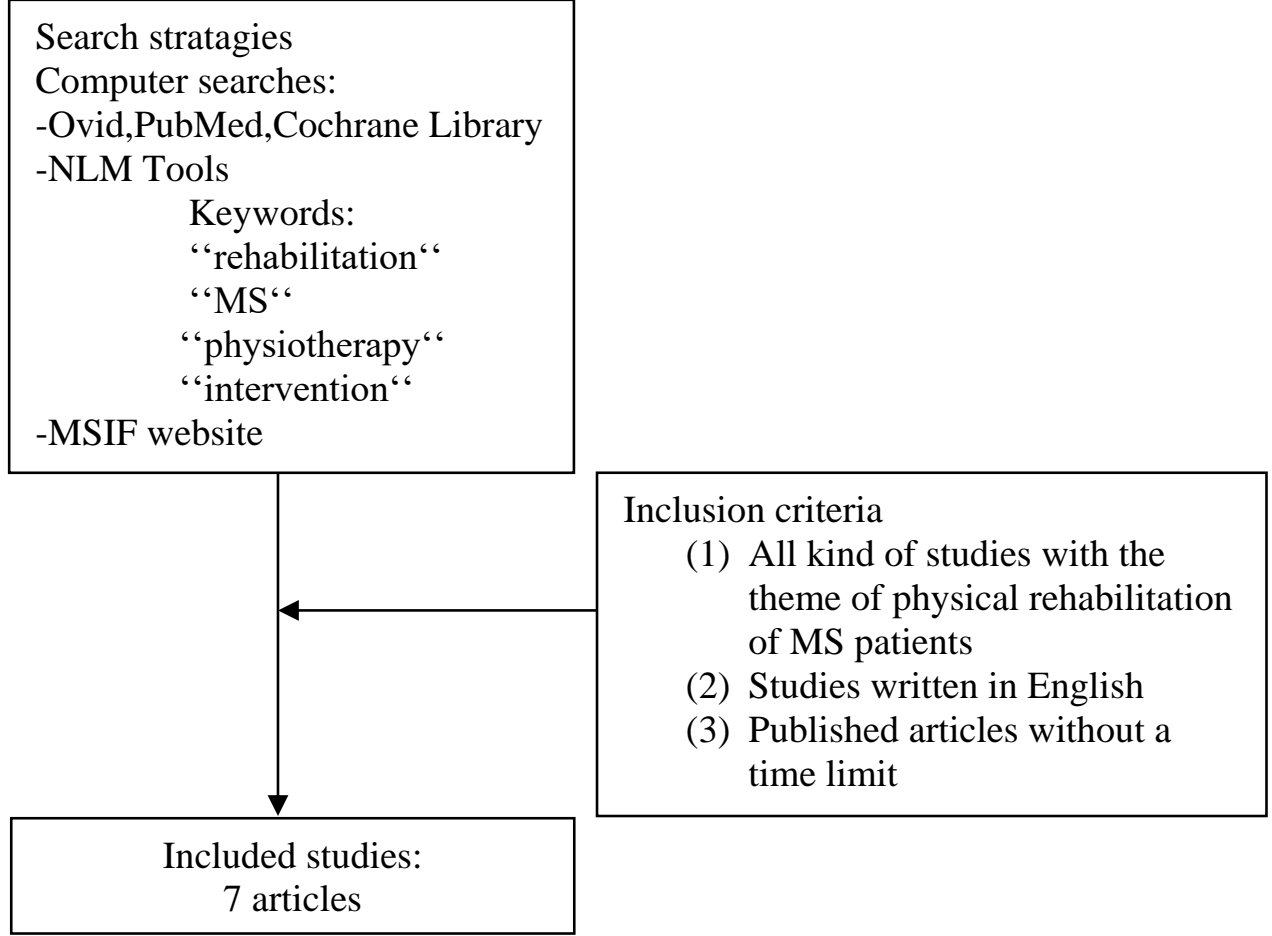

Figure 1. Flow diagram of study selection

\section{The inclusion and exclusion criteria, categorization and data syntheses}

The process of research resulted in the identification of more than thirty potential articles but in the analyses we included only the results of seven original articles related to theme of rehabilitation of MS. The evaluation of the quality was done using the criteria of quality evaluation (Kmet LM et al., 2004). The categorization was performed: using the first author and the publishing year, method and final results. The application of the meta-analyses was not possible as for the heterogeneity of the method. However, analyzing was focused on the identification of the important results related to the chosen factor which was the rehabilitation of the MS patients. Ranking of the articles was done according to the publishing year. 


\section{Inclusion criteria}

- The inclusion criteria were the published studies with the theme of rehabilitation of MS patients including the systematic review of the literature.

\section{Exclusion criteria}

- $\quad$ The research excluded dissertations and book chapters.

\section{Results and discussion}

The results included the results of seven articles. The analyses showed that MS affects more women than men. (Table 1)

Table 1. Presentation of data analyses

\begin{tabular}{|c|c|c|}
\hline $\begin{array}{l}\text { The first author and the } \\
\text { publishing year }\end{array}$ & Methods & Main results \\
\hline 1.Terré-Boliart R . et al. (2007) & $\begin{array}{l}\text { Literature review in } \\
\text { rehabilitation therapy and } \\
\text { the clinical studies } \\
\text { conducted to evaluate the } \\
\text { effectiveness of the } \\
\text { rehabilitation therapy and } \\
\text { the more common } \\
\text { symptoms }\end{array}$ & $\begin{array}{l}\text { Most of the studies report } \\
\text { improvement of the limited } \\
\text { disability and life quality, } \\
\text { while the deficit remains } \\
\text { unchanged. } \\
\text { Each achieved improvement } \\
\text { tends to reduce with time, } \\
\text { which makes it necessary to } \\
\text { be followed even after } \\
\text { finishing the therapy. } \\
\text { Symptoms such as fatigue, } \\
\text { spasticity, ataxy and } \\
\text { sphyncter disorders profit } \\
\text { from the proper } \\
\text { pharmacological treatment } \\
\text { applied together with the } \\
\text { rehabilitation therapy. }\end{array}$ \\
\hline \multirow[b]{2}{*}{ 2.Vikman, T et al. (2009) } & $\begin{array}{l}\text { An evaluation study for } \\
\text { three weeks including two }\end{array}$ & $\begin{array}{c}\text { As a result after a three } \\
\text { week rehabilitation period } \\
\text { were noted improvement of } \\
\text { the stationary rehabilitation } \\
\text { in the motor functions and } \\
\text { other aspects }\end{array}$ \\
\hline & $\begin{array}{l}\text { groups } \mathrm{A}(\mathrm{n}=40) \text {, and } \mathrm{B} \\
(\mathrm{n}=18) \text { and application of } \\
\text { rehabilitation techniques. }\end{array}$ & $\begin{array}{l}\text { There were little data found } \\
\text { on the efficacy of the } \\
\text { special exercises and } \\
\text { physical therapy based on } \\
\text { programs for the } \\
\text { individualized problem } \\
\text { solving, the resistance and } \\
\text { aerobic exercises on the } \\
\text { improvement of the balance } \\
\text { in MS ambulatory patients. }\end{array}$ \\
\hline 3.Paltamaa $\mathrm{J}^{1}$, , et al. oct. 2012 & & $\begin{array}{l}\text { The results of the surveys } \\
\text { refer that the exercises }\end{array}$ \\
\hline
\end{tabular}




\section{Literature review with 54 articles from 4362 identified.}

4.Latimer-Cheung $\mathrm{AE}^{1}$,. et al. (2013)

5.Mitolo, et al. (2015)

6. Campbell $\mathrm{E}^{1}$,. et al. (2015)

7.K T Hanssen (2016)

A systematic review of the literature related to the correlation between the damage of the cognitive and the later ones and the techniques.

A systematic review of the literature of 30 abstracts 120 people (divided in the control group and the case group) with complaints of the cognitive area underwent a multidisciplinary performed two times a week with moderate intensity increase the aerobic capacity and muscular strength.

The data refer that cognitive ability, image, mood, fatigue, life quality and deficit of self perception were the inclusive criteria for the articles, these signs were improved after the rehabilitation

Executive functioning abilities in the early phases

A case control study where rehabilitation period of four weeks. improved significantly from baseline to four and 7 months in both groups (intervention and control group). Improvements in psychological well-being and psychological aspects of HRQoL occurred only in the intervention group.

The rehabilitation was performed through eight interventions, excercise therapy, multidisciplinary rehabilitation, functional electrical stimulation, injection with botuline of type A and manual streches, training of inspiratory muscles, gait therapy, acupuncture, and maintaining the body weight through the routine training. 
The rehabilitation of the MS patients is necessary but also very complex, it requires a personalized and multidisciplinary care. The modern medical treatment is not the only way that can postpone the progressive neurodegenerative processes and still remains unclear up to where this treatment prevents the loss of the functional abilities (Nedeljkovic $\mathrm{U}$ et al., 2015).

Similar reviews of the literature highlighted similar results, emphasizing that in a psychological intervention physiotherapy treatments are safe and effective for the rehabilitation of neurological patients (Castelnuovo G. et al., 2015).The rehabilitation services remain as important as the pharmacological ones in MS patients. Rehabilitation (Donzé et al., 2015) like other therapies needs regular and continuous clinical evaluations in order to adapt to the program and proper techniques. What is more important is the fact that the rehabilitation should be individual and have real expectations. There were improvement of the stationary rehabilitation in motor functions and other aspects.

\section{Limitations of the Study}

The effect of physical rehabilitation in MS patients need interpretation with caution due the difference in the type of methods of studies selected for the review. Only articles in English were included in this review, and most of the studies included for analysis were literature review.

\section{Conclusion}

The analyzed studies point out that rehabilitation is a very important therapy, especially in the appearance of symptoms during the evolutionary chronic phase when MS has affected the physical side as well as the social and psychological ones. The literature review noted that MS multidisciplinary rehabilitation is effective in improving the capacity for daily activities and reducing the disability. Rehabilitation is able to improve the damages and neurological signs.

What we should emphasize is that in almost the majority of studies included, rehabilitation should be performed by a trained team of professionals (physiotherapists, occupational therapist, speech therapist, rehabilitation of the sphincter disorders). The importance of rehabilitative therapy for MS patients lies in its ability to improve limited disability and quality of life so that its effects are not lost over time.

Contradictory findings were identified in the published literature regarding the effectiveness of various forms of cognitive rehabilitation techniques used in patients with MS. Better methodological studies are needed to clarify which form of cognitive rehabilitation can lead to greater clinical improvement. 


\section{References:}

Ann Pietrangelo and Valencia Higuera (2015). Medically Reviewed by Steven Kim, MD on March 24, 2015. http://www.healthline.com/health/multiple-sclerosis/facts-statisticsinfographic\#sthash.UWgNFDwg.dpuf NIH: National Institute of Neurological Disorders and Stroke. (2001). Alberto Gajofatto, Massimiliano Calabrese, Maria Donata Benedetti, and Salvatore Monaco (2013), "Clinical, MRI, and CSF Markers of Disability Progression in Multiple Sclerosis," Disease Markers, vol. 35, no. 6, Article ID 484959, 13 pages, 2013.

MSFocus, Vol.15.Issue 3.Summer 2013.

WHO (2008) Atlas multiple sclerosis resources in the World 2008 ISBN 978 9241563758 (NLM classification: WL 360)

MSIF; Multiple Sclerosis International Federation 2013. http://www.msif.org/wp-content/uploads/2014/09/Atlas-of-MS.pdf

Kruja J, Beghi E, Zerbi D, Dobi D, Kuqo A, Zekja I, Mijo S, Kapisyzi M, Messina P (2012). High prevalence of major neurological disorders in two Albanian communities: results of a door-to-door survey. Neuroepidemiology. 2012;38 (3):138-47.

MS in Focus, Ageing with MS January 2015 ISSN1478467x (C) MS International Federation

Higgins J, Green S. (2008). Cochrane handbook for systematic reviews of interventions. Wiley, Chichester (UK) 2008.

Kmet LM, Lee RC, Cook LS. (2004). Standard quality assessment criteria for evaluating primary research papers from a variety of fields. Alberta Heritage Foundation for Medical Research: Edmonton, 2004.

Terré-Boliart R, Orient-López F. (2007). [Rehabilitation therapy in multiple sclerosis]. Rev Neurol. 2007 Apr 1-15;44(7):426-31. Review.

T. Vikman, P. Fielding, B. Lindmark \& S. Fredrikson (2009). Effects of inpatient rehabilitation in multiple sclerosis patients with moderate disability : pages 58-65 11 Jul 2009

Paltamaa J, Sjögren T, Peurala SH, Heinonen A. (2012). Effects of physiotherapy interventions on balance in multiple sclerosis: a systematic review and meta-analysis of randomized controlled trials. J Rehabil Med. 2012 Oct;44(10):811-23.

Latimer-Cheung AE, Pilutti LA, Hicks AL, Martin Ginis KA, Fenuta AM, MacKibbon KA, Motl RW.(2013). Effects of exercise training on fitness, mobility, fatigue, and health-related quality of life among adults with multiple sclerosis: a systematic review to inform guideline development. Arch Phys Med Rehabil. 2013 Sep;94 (9):1800-1828. 
Mitolo M, Venneri A, Wilkinson ID, Sharrack B. (2015).Cognitive rehabilitation in multiple sclerosis: A systematic review. J Neurol Sci. 2015 Jul 15;354 (1-2):1-9.

Campbell E, Coulter EH, Mattison PG, Miller L, McFadyen A, Paul L. (2016). Physiotherapy Rehabilitation for People With Progressive Multiple Sclerosis: A Systematic Review. Arch Phys Med Rehabil. 2016 Jan;97(1):141-151.

K T Hanssen, A G Beiske, N I Landro, D Hofoss, E Hessen. (2016). Cognitive rehabilitation in multiple sclerosis: a randomized controlled trial. Acta Neurologica Scandinavica Vol. 133, Issue 1. Date: 01/01/2016 Start Page: 30.

Nedeljkovic U, Raspopovic ED, Ilic N, Vujadinovic ST, Soldatovic I, Drulovic J. (2015). Effectiveness of rehabilitation in multiple sclerosis relapse on fatigue, self-efficacy and physical activity. Acta Neurol Belg. 2015 Nov 12.

Castelnuovo G, Giusti EM, Manzoni GM, et al. (2015). Effectiveness of rehabilitation in multiple sclerosis relapse on fatigue, self-efficacy and physical activity. Acta Neurol Belg. 2015 Nov 12. [Epub ahead of print] PubMed PMID: 26563405. Psychol. 2016 Feb 19;7:115.

Donzé, Cécile La Presse Médicale. (2015). Update on rehabilitation in multiple sclerosis; Volume 44, Issue 4, Part 2, April 2015, e169-e176. 